\title{
Prevalence and Pattern of Third Molar Impaction in Sample of Yemeni Adults
}

\author{
Yahya Alhadi ${ }^{1}$, Hassan Abdulwahab Al-Shamahy ${ }^{2 *}$, Abdullwahab Aldilami ${ }^{1}$, Mohsen Al-Hamzy ${ }^{3}$, Khaled \\ Abdulsalam Al-Haddad ${ }^{4}$ and Mohammed Shaalan ${ }^{1}$ \\ ${ }^{1}$ Department of Oral and Maxillo-Facial Surgery, Faculty of Dentistry, Sana'a Univeristy, Republic of Yemen \\ ${ }^{2}$ Department of Basic Sciences, Faculty of Dentistry, Republic of Yemen \\ ${ }^{3}$ Department of Conservative Dentistry and Oral Health, Republic of Yemen \\ ${ }^{4}$ Department of Orthodontic and Pediatric Dentistry, Republic of Yemen
}

*Corresponding author: Hassan A Al-Shamahy, Department of Basic Sciences Faculty of Dentistry, Sana'a University, Yemen.

Received Date: February 22, 2019

Published Date: March 13, 2019

\begin{abstract}
Background and objectives: Third molar impaction is an important clinical issue because impacted teeth predispose to periodontal disease such as pericoronitis, periodontitis, and other problems such as cystic lesions, neoplasm, root resorption and can cause detrimental effects on adjacent tooth resulting in pain, discomfort and loss of function. The pattern of third molar impaction in Yemeni population has not been described; thus, the aim of this retrospective radiographic study was to determine the prevalence and pattern of third molar impaction, angulation and level of eruption in sample of Yemeni adults.
\end{abstract}

Materials and methods: The study sample of 609 patients chosen randomly from patients who visited MASS x-ray centers in Sana'a and Ibb cities. The data collected included presence and impaction state, angulation, and depth of impaction of third molars.

Results: Out of total population, $236(38.8 \%)$ showed at least one impacted third molar. The condition was slightly higher in females (40\%) than in male (35.1\%). The incidence of impacted lower third molars were most frequent $(22.8 \%)$ than impacted upper third molar (15.9\%). The most common level of impacted third molars was level II (43.8\%) the most common angulation of impaction in the mandible was the mesioangular (76.8\%), the most common level of impaction was level II (43.8\%) and position of impaction was B (72.6\%). There was no significant difference in the frequency of impaction between the right and left sides of both jaws.

Conclusion: This study found that about $40 \%$ of Yemeni adult patients ranging in age from 18-28 years had at least one impacted third molar.

Keywords: Radiography, Panoramic; Third-Molar, Impacted Teeth; prevalence, Yemen

\section{Introduction}

Teeth grow to be impacted when they fail to erupt or develop in their proper functional location. Also; of all teeth, mandibular third molars are the most frequently impacted [1]. The tooth fails to erupt completely or partially to its correct position in the dental arch and its eruption potential has been lost and will not eventually assume a normal arch relationship with the other teeth and tissues. Many theories have been proposed owing to the causes of teeth impaction. One of them is the inadequate space in the dental arch for eruption as stated by the Phylogenic theory: due to evolution, the human jaw size is becoming smaller and since the third molar tooth is last to erupt, there may not be room for it to emerge in the oral cavity then impacted teeth can be seen, because of lack of space [2]. Also, one of the most popular theory in high incidence of mandibular third molar impaction is insufficient development of the retromolar space $[3,4]$. Mandibular ramus growth is related to resorption at its anterior surface and deposition at its posterior surface, but in case of imbalance of this process, the mandibular third molars do not get enough space to erupt [5]. Third molar impaction is an important clinical issue because impacted teeth predispose to periodontal disease such as pericoronitis, periodontitis, and other problems 
such as cystic lesions, neoplasm, root resorption and can cause detrimental effects on adjacent tooth resulting in pain, discomfort and loss of function [6]. The prevalence of third molar impaction in the human race usually ranges from $27-68.6 \%$ [7-9]. A few studies from the Arabic countries have reported the prevalence of impacted third molars to be 32-40.5\% [8,9]. The pattern of third molar impaction in Yemeni population has not been described; thus, the aim of this retrospective radiographic study was to determine the prevalence and pattern of third molar impaction, angulation and level of eruption in sample of Yemeni population.

\section{Subjects and Methods}

Digital panoramic images obtained from a Sample of Yemeni Adult, the sample were collected in Sana'a and Ibb cities, which represent the largest population cities in Yemen. The sample 609 was selected from the data records of (MASS x-ray center) randomly, in which they meet the study criteria from January 2014 to December 2017. The panoramic radiographs utilized were taken with the same equipment Vactch (PaX-400C); the exposure settings were $90 \mathrm{kVp}, 10 \mathrm{~mA}$ and the focal spot is $0,5 \mathrm{~mm}$, varying according to the age and biotype. Panoramic radiographs were stored in software form. Therefore, no alterations related to storage conditions was occurred. All destroyed or defected and artifacted radiographs were not included in this study, also radiographs in which the second molar is missing for any reason were not included in the study. Data was recorded in a special form and two reference lines were made with the adjacent second molar. The first one is drawn with the longitudinal axes of the adjacent second molar and the second is drawn with the longitudinal axes of the impacted 3rd molar to determine impaction position. Classification and the relationship of the upper part of the crown of the impacted tooth to the occlusal surface of the adjacent fully erupted second molar was used to determine the levels of the impacted teeth.

According to Winter's classification, third molars are classified according to their inclination to the long axis of the second molar [10] as following:

- M: Mesioangular

- H: Horizontal

- D: Distoangular

- V: Vertical

- $\quad$ I: Inverted

According to Pell and Gregory classification system [11], where the impacted teeth are assessed according to their relationship to the occlusal surface (OS) of the adjacent second molar, and the relation of the third mandibular molar to the ramus of mandible and second molar as following:
Class I: Sufficient amount of space for accommodation mesiodistally of the crown of the third molar

Class II: The space between the ramus and distal side of second molar is, less than the mesiodistal diameter of the third molar.

Class III: The third molars is located within the ramus.

\section{Classification according to the relative depth of the third mandibular molar in the bone}

Position A: The highest portion of the impacted tooth is on a level with/above the occlusal line

Position B: The highest portion of the impacted tooth is below the occlusal plane, but above the cervical line of the second molar

Position C: The highest portion of the impacted tooth below the cervical line of the second molar teeth in relation to the long axis of impacted second molar.

For the impaction of upper third molar according to Archer's classification [11], they were classified as following:

- Sinus approximation: no bone or thin partition of bone between impacted maxillary third molar and maxillary sinus less than $2 \mathrm{~mm}$

- $\quad$ No sinus approximation: $2 \mathrm{~mm}$ of bone between impacted maxillary third molar and maxillary sinus

\section{Data analysis}

Data was analyzed using SPSS program (version23). Frequency, distribution was generated to describe the prevalence and pattern of third molar impaction.

\section{Ethical approval}

Ethical approval was obtained from the Medical Research \& Ethics Committee of the Faculty of Medicine \& Health Sciences at Sana'a University. All data, including patient identification and X-rays, were kept confidential.

\section{Results}

Table 1 presents the distribution of fully erupted and impacted third molars by arch and gender; and association of impacted third molars arch with gender, A total of 236 (38.8\%) patients had all third molars impacted, the prevalence of impacted mandible third molars (15.9\%) was slightly lower than that of impacted maxillary third molars $(22.8 \%)$ which was statistically significant $(\mathrm{p}<0.05)$. The prevalence of impacted third molars in females (40\%) was slightly higher than that of males (35.1\%) which was statistically insignificant $(\mathrm{p}=0.23)$. In the maxilla, females $(17.9 \%)$ had more impacted third molar teeth than males (10.9\%). In the mandible, females $(22.1 \%)$ had slightly similar rate of impacted third molar teeth of males $(24.1 \%)$ (Table 1$)$.

Table 1: Distribution of fully erupted and impacted third molars by arch and gender; and association of impacted third molars arch with gender.

\begin{tabular}{|c|c|c|c|c|c|c|}
\hline Gender & Impacted Upper (Maxilla) & Impacted Lower (Mandible) & Total Impacted & OR & CI $95 \%$ & $\mathbf{P}$ \\
\hline Male $n=174$ & $19(10.9 \%)$ & $42(24.1 \%)$ & $61(35.1)$ & 0.8 & $0.5-1.6$ & 0.23 \\
\hline Female $n=435$ & $78(17.9 \%)$ & $96(22.1 \%)$ & $174(40 \%)$ & 1.2 & $0.8-1.7$ & 0.23 \\
\hline Total $n=609$ & 97 (15.9\%) & 139 (22.8\%) & $236(38.8 \%)$ & & & \\
\hline
\end{tabular}


Table 2 shows the distribution of impacted third molars by jaw and side of the jaw; and association of impacted third molars arches with side of the jaw. There was no statistically significant difference between the right and left impacted third molars within each arch (Table 2).

Table 2: Distribution of impacted third molars by jaw and side of the jaw; and association of impacted third molars arch with side of the jaw.

\begin{tabular}{|c|c|c|c|c|c|c|}
\hline Side of the Jaw & Impacted Upper (Maxilla) & Impacted Lower (Mandible) & Total Impacted & OR & CI 95\% & P \\
\hline Right $\mathrm{n}=609$ & $69(11.3 \%)$ & $49(8 \%)$ & $118(19.4 \%)$ & 0.8 & $0.4-1.4$ & 0.51 \\
\hline Left $\mathrm{n}=609$ & $70(11.5 \%)$ & $48(8 \%)$ & $118(19.5 \%)$ & 1.2 & $0.7-2$ & 0.51 \\
\hline Total $\mathrm{n}=609$ & $139(22.8 \%)$ & $97(16 \%)$ & $236(38.8 \%)$ & & & \\
\hline
\end{tabular}

Table 3 presents the distribution of impacted third molars by angulations and side of the jaw; and association of impacted third molars with angulations types. Overall, mesioangular impaction

was the most frequent $(76.3 \%)$, with associated odds ratio equal to 8.4 times and $95 \% \mathrm{CI}=5.4-13(\mathrm{p}<0.001)$, followed by vertical (22.3\%); while distoangular was rare (1.4\%) (Table 3).

Table 3: Distribution of impacted third molars by angulations and side of the jaw; and association of impacted third molars with angulations types.

\begin{tabular}{|c|c|c|c|c|c|c|}
\hline Angulations & Right $n=69$ & Left $n=70$ & Total $n=139$ & OR & CI $95 \%$ & $\mathbf{P}$ \\
\hline Mesioangular & $53(76.8 \%)$ & $53(75.7 \%)$ & 106 (76.3\%) & 8.4 & $5.4-13$ & $<0.001$ \\
\hline Verticle & $14(20.3 \%)$ & 17 (24.3\%) & $31(22.3 \%)$ & 0.37 & $0.1-0.5$ & $<0.001$ \\
\hline Destoangular & $2(2.9 \%)$ & $0(0 \%)$ & $2(1.4 \%)$ & 0.01 & 0.001-0.06 & $<0.001$ \\
\hline
\end{tabular}

Table 4 presents the distribution of impacted third molars by level of impaction and side of the jaw; and association of impacted third molars with level of impaction. Overall, B position of impaction was the most common one $(72.8 \%)$, with associated odds ratio

equal to 6.5 times and $95 \% \mathrm{CI}=4.3-10(\mathrm{p}<0.001)$, followed by $\mathrm{C}$ position $(25.1 \%)(\mathrm{p}<0.001)$; while A position was rare $(2.15 \%)$ $(\mathrm{p}<0.001)$ (Table $4 \& 5)$.

Table 4: Distribution of impacted third molars by level of impaction and side of the jaw; and association of impacted third molars with level of impaction.

\begin{tabular}{|c|c|c|c|c|c|c|}
\hline Level of Impaction & Right $\mathbf{n = 6 9}$ & Left n=70 & Total $\mathbf{n = 1 3 9}$ & OR & CI 95\% & P \\
\hline I & $30(43.5 \%)$ & $22(31.4 \%)$ & $52(37.4 \%)$ & 0.9 & $0.6-1.3$ & 0.7 \\
\hline II & $29(42 \%)$ & $32(45.7 \%)$ & $61(43.8 \%)$ & 1.3 & $0.8-1.9$ & 1.9 \\
\hline III & $10(14.5 \%)$ & $16(22.9 \%)$ & $26(18.7 \%)$ & 0.2 & $0.1-0.4$ & $<0.001$ \\
\hline
\end{tabular}

Table 5: Distribution of impacted third molars by position and side of the jaw; and association of impacted third molars with position of impaction.

\begin{tabular}{|c|c|c|c|c|c|c|}
\hline Positions & Right $\mathbf{n = 6 9}$ & Left $\mathbf{n = 7 0}$ & Total $\mathbf{n = 1 3 9}$ & OR & CI 95\% & P \\
\hline A & $2(2.9 \%)$ & $1(1.4 \%)$ & $3(2.15 \%)$ & 0.02 & $0.007-0.07$ & $<0.001$ \\
\hline B & $50(72.5 \%)$ & $51(72.8 \%)$ & $101(72.6 \%)$ & 6.5 & $4.3-10$ & $<0.001$ \\
\hline C & $17(24.6 \%)$ & $18(25.8 \%)$ & $35(25.17 \%)$ & 0.4 & $0.2-0.6$ & $<0.001$ \\
\hline
\end{tabular}

\section{Discussion}

This is the first study to estimate the rate of third molar impaction in Yemen. A total of 609 patients were investigated for impacted upper and lower third molars. We recovered that $38.8 \%$ of patients had at least one impacted third molar, indicating how common impaction is and the need to discover the possible aetiological factors of this condition. This will assist decide whether this is an emerging problem or as a result of influences of the population's ethnic background. The aetiology of third molar impaction has never been investigated among Yemeni population and there is a need to conduct future studies to assess the causes of this condition more extensively. In our study the prevalence of third molar impaction was (38.8\%), which in other studies showed the prevalence of third molar impaction ranges from $16.7 \%$ to $68.6 \%$ [8,12-15].

The prevalence in Yemen according to our study was slightly higher than that reported by Fanning, et al. [16] in [Australia (30.3\%), and by Kramer and Williams in UK (33\%) [17], On the other hand, it is less than that reported by Morris and Jerman [18] and Quek et al.
[8], who reported frequencies of $65.6 \%$ in a study of 5000 subjects in United States of America and 68.6\% in a sample of 1000 subjects in Singapore[8].This difference may be explained by the fact that the genetic and racial differences are the two important factors in tooth impaction. Most studies have reported no gender predilection in third molar impaction $[12,14,16]$. But in our study there was a slightly higher rate in females (40\%) compared to $35.1 \%$ ) in male. Also some other studies, however, have reported a higher frequency in females than males [17-19].

Mandibular third molars were the most frequently impacted (22.82\%), with the Mesioangular type of impaction was the most common. Like other studies carried in Pakistan, USA, Nigeria, China, Thailand, Spain and Malaysia, where the most common type was mesioangular impactions [20-22]. Class 2 level of impaction (43.8\%) and the position B (72.6\%) were the most common impactions like those reported in other studies $[9,23]$. Radiological examination of our patients revealed that mesioangular impaction was the most common type of angulation (76.3\%) Table 3. This is in agreement with many other studies where the frequency of 
mesioangular impaction was the common type of angulations [9,22-28].

However, the current study's results differ from study published by Reddy et al. [7] which found that vertical impaction was the most common type of third molar impaction. This could be due to the fact that a different method of classifying angulation was used in the current study. Another study classified angulation according to visual impressions based on Winter's classification method. In the current study, vertical impaction was observed in $22.3 \%$, which is less than the findings of Byahatti et al. (38\%) [25] and Sandhu et al. (42\%) [23] in Libyan and Asian-Indian populations, respectively. An analysis of the level of impaction showed that level B was the most common level of impaction (72.6\%). This agrees with the results of other research which reported that level B was the most common level of impaction $[9,23]$.

\section{Conclusion}

Our study is the first retrospective radiographic study determine the prevalence of third molar impaction in young Yemeni adults. A slightly higher prevalence found, with $38.8 \%$ of these Yemeni adult patients having at least one impacted third molar, highlights the required to raise awareness among dental practiced. More studies should be carried out to decide how many patients with impacted third molars are symptomatic or actively look for treatment. Additional studies are required to determine the pattern of third molar impaction in other regions of Yemen.

\section{Acknowledgment}

The authors would like to acknowledge Sana'a University, Sana'a, Yemen which supported this work.

\section{Conflict of Interest}

No conflict of interest associated with this work.

\section{References}

1. Dimitroulis G (1996) A Synopsis of Minor Oral Surgery. ButterworthHeinemann Publishing $4^{\text {th }}$ edn, Oxford, UK, 48-57.

2. Neelima Anil Malik (2012) Principles of management of impacted teeth. Textbook of Oral and Maxillofacial Surgery $3^{\text {rd }}(\mathrm{ed})$, India,145-146.

3. Bishara SE, Andreasen G (1983) Third molars: a review. Am J Orthod 83(2): 131-137.

4. Grover PS, Lorton L (1985) The incidence of unerupted permanent teeth and related clinical cases. Oral Surg Oral Med Oral Pathol 59(4): 420425.

5. Björk A (1969) Prediction of mandibular growth rotation. Am J Orthod 55(6): 585-599.

6. Odusanya SA, Abayomi IO (1991) Third molar eruption among rural Nigerians. Oral Surg Oral Med Oral Pathol 71(2): 151-154.

7. Reddy KVG, Prasad KVV (2011) Prevalence of third molar impactions in urban population of age 22-30 years in South India: An epidemological study. J Indian Dent Assoc 5: 609-611.
8. Quek SL, Tay CK, Tay KH, Toh SL, Lim KC (2003) Pattern of third molar impaction in a Singapore Chinese population: A retrospective radiographic survey. Int J Oral Maxillofac Surg 32(5): 548-552.

9. Hassan $\mathrm{AH}$ (2010) Pattern of third molar impaction in a Saudi population. Clin Cosmet Investig Dent 2: 109-113.

10. Winter GB (1926) Impacted mandibular third molars. St Louis: American Medical Book Co, pp. 241-279.

11. Archer HW (1975) Oral and Maxillofacial Surgery $5^{\text {th }}$ edn. In: WB Saunders (Ed.), Philadelphia, USA, p. 311.

12. Kaya GS, Aslan M, Ömezli MM, Dayi E (2010) Some morphological features related to mandibular third molar impaction. Journal of Clinical and Experimental Dentistry 2(1): e12-e17.

13. Hattab FN, Rawashdeh MA, Fahmy MS (1995) Impaction status of third molars in Jordanian students. Oral Surg Oral Med Oral Pathol Radiol Endod 79(1): 24-29.

14. Scherstén E, Lysell L, Rohlin M (1989) Prevalence of impacted third molars in dental students. Swed Dent J 13(1-2): 7-13.

15. Brown LH, Berkman S, Cohen D, Kaplan AL, Rosenberg M (1982) A radiological study of the frequency and distribution of impacted teeth. J Dent Assoc S Afr 37(9): 627-630.

16. Fanning EA, Moorrees CF (1969) A comparison of permanent mandibular molar formation in Australian aborigines and Caucasoids. Arch Oral Biol 14(9): 999-1006.

17. Kramer RM, Williams AC (1970) The incidence of impacted teeth. A survey at Harlem hospital. Oral Surg Oral Med Oral Pathol 29(2): 237241.

18. Morris CR, Jerman AC (1971) Panoramic radiographic survey: a study of embedded third molars. J Oral Surg 29(2): 122-125.

19. Bishara SE (1992) Impacted maxillary canines: a review. Am J Orthod Dentofacial Orthop 101(2): 159-171.

20. Bui CH, Seldin EB, Dodson TB (2003) Types, frequencies and risk factors for complications after third molar extraction. J Oral Maxillofac Surg 61(12): 1379-1389.

21. Unwerawattana W (2006) Common symptoms and type of impacted molar tooth in King Chulalongkorn Memorial Hospital. J Med Assoc Thai 89(3): S134-139.

22. Chaparro Avendaño AV, Pérez García S, Valmaseda Castellón E, Berini Aytés L, Gay Escoda C (2005) Morbidity of third molar extraction in patients between 12 and 18 years of age. Med Oral Patol Oral Cir Bucal 10(5): 422-431.

23. Sandhu S, Kaur T (2005) Radiographic evaluation of the status of third molars in the Asian-Indian students. J Oral Maxillofac Surg 63(5): 640645.

24. Ma'aita JK (2000) Impacted third molars and associated pathology in Jordanian patients. Saudi Dent J 12: 16-19.3b.

25. Byahatti S, Ingafou MSH (2012) Prevalence of eruption status in third molars in Libyan students. Dent Res J (Isfahan) 9(2): 152-157.

26. Obiechina AE, Arotiba JB, Fasola AO (2001) Third molar impaction: Evaluation of the symptoms and pattern of impaction of mandibular third molar teeth in Nigerians. Odontostomatol Tropic 24(93): 22-25.

27. Jaffar RO, Tin Oo MM (2009) Impacted mandibular third molars among patients attending Hospital Universiti Sains Malaysia. Archives of Orofacial Sciences 4(1): 7-12.

28. Mwaniki D, Guthua SW (1996) Incidence of impacted mandibular third molars among dental patients in Nairobi, Kenya. Odonto-Stomatologie Tropicale 19: 17-19. 